\title{
On visibility: AIDS, deception by patients, and the responsibility of the doctor
}

\author{
Scott Dunbar and Susan Rehm Cleveland Clinic Foundation, Ohio, USA
}

\section{Authors' abstract}

Contrary to the usual discussion of lying or deceiving in medical ethics literature where the lying or deceiving is done by the doctor or surgeon, this paper deals with lying or deceiving on the part of the patient. Three cases involving $H I V$-infected male homosexual or bisexual persons are presented. In each case the patient deceives or wants the doctor to deceive a third party on his behalf. Are such deceptions or lies expressions of compassion? Are they in the patient's best interests? Do they compromise the doctor's integrity? It is submitted that societal attitudes towards male homosexual acts were internalised by the men described in these cases. Thus, a dichotomy was created between the private life and the public image. Fear of condemnation by the doctor or others restricted communication towards the goal of the maintenance of the patient's health. The lack of trust which inhibits truthtelling results in mutual and progressive isolation and impedes the provision of optimal care.

Typically, when the topic of lying or deceiving is discussed in medical ethics literature, invariably the lying or deceiving is on the part of a doctor towards a patient. Consider the case of Mrs J who was admitted to the hospital at the request of her family doctor with severe chest pains. $\mathrm{Dr} \mathrm{H}$, the family doctor, was quite sure that Mrs J had had a severe heart attack. Three weeks later however, $\mathrm{Mr} \mathrm{J}$ came to the doctor's office to tell him that his wife had cancer and 'it was only a matter of time'. 'The only blessing is,' he continued, 'that she knows nothing about it.' During the preceding three-week period Mr J had been informed by the surgeon in charge that his wife had cancer and that 'it was only a matter of time'. Mr J asked the surgeon not to tell his wife and the surgeon agreed. The surgeon told the patient she had a 'fungus infection' and that he had removed it. He did not tell her that she had cancer.

Whether the surgeon would have lied or deceived the patient had her husband not asked him to do so, or

\section{Key words}

Patient-determined deception; HIV infection; male homosexuality; societal background; doctor integrity; truth-telling; trust; confidentiality; autonomy. would have deceived $\mathrm{Mr} \mathrm{J}$, had he been the patient rather than his wife, or whether a woman surgeon would have deceived Mrs J are significant questions involving, inter alia myths of gender. As these questions have been discussed elsewhere (1), they need not detain us here (for the purpose of mentioning this case is to illustrate the initial point, namely, that when deceiving or lying is discussed in the literature the doctor is invariably the party who lies to, or who deceives, the patient).

What we want to do in this paper is to correct the omission noted above, namely to discuss situations in which the patient lies or deceives and/or expressly or deceptively requests the doctor to participate in and propagate a lie or deception, ostensibly for the patient's best interests or because of the patient's concern about the feelings of others. We shall do so by presenting three cases. All three cases discuss men who became HIV-infected through homosexual activity. Our scope of experience does not allow us to speculate on the prevalence of deception of health-care providers among individuals who acquire HIV infection in other ways.

Before presenting the cases we shall sketch in something of the legal-societal background which engenders pejorative attitudes towards homosexual males, and thus engenders the lying and deceiving one finds among HIV-infected individuals. Societal feelings, attitudes and actions against male homosexuals did not simply erupt in contemporary society, any more than they were created by the unexpected presence of the AIDS pandemic. The pejorative feelings, attitudes and actions, are deeply rooted in the history of western civilisation which has been shaped by the Judaeo-Christian religious tradition. Susan Sontag, in AIDS and its Metaphors got at most a half-truth right when she suggested that societal feeling is not against AIDS, but against the means by which such persons became infected. The crucial factor Sontag missed is the societal feeling against the existence of individuals with alternative lifestyles. It is this factor which facilitates attitudes against people with AIDS that is not present with most other diseases. It is this factor which makes AIDS a triply stigmatic illness: the stigma of an infectious deadly disease; the stigma of having engaged in homosexual behaviour; 
and the stigma of being a homosexual.

The US Supreme Court in Bowers v Hardwick (1986) in a 5-4 decision upheld the constitutionality of Georgia's sodomy statute (2). The majority opinion of the court held that the constitution does not protect sexual relations between two consenting adult males even in the privacy of their own bedroom or home. Sodomy is defined by the Georgia statute as 'any sexual act involving the sex organs of one person and the mouth or anus of the other'. The Georgia statute applies to heterosexual couples, women as well as men, but the court expressed no opinion on the constitutional protection of sodomy between heterosexual couples. The focus in Bowers v Hardwick is solely the issue of sexual conduct between consenting males.

Delivering the majority opinion, Justice White said: 'Proscriptions against ... [homosexuals engaging in the acts of consensual sodomy] ... have ancient roots' (3), and then rejected as 'facetious' the argument that the Georgia statute violates the constitutional right to privacy because it punishes choice in matters of personal intimate associations, choice which produces no discernible harm. At the time of the court's decision (1986) 25 other states and the District of Columbia had laws which criminalised sodomy in private between consenting adults.

Chief Justice Burger expressed the hostility of the court toward homosexuals when he said: 'Decisions of individuals relating to homosexual conduct have been subject to state intervention throughout the history of western civilisation. Condemnation of these practices is firmly rooted in Judaeo-Christian moral and ethical standards' (4).

He concluded by describing homosexual conduct as 'heinous' and asserted that to protect homosexual conduct 'as a fundamental right would be to cast aside millenia of moral teaching'.

Dissenting from the majority opinion, Justice Blackmun observed that the court had refused to recognise the fundamental interest all individuals have in controlling the nature of their intimate associations with others:

'[T] he right of an individual to conduct intimate relationships in the intimacy of his or her own home [is] the heart of the constitution's protection of privacy' (5).

Earlier in this paper we said that we wanted to sketch in something of the societal background which engenders pejorative feelings, attitudes and actions towards homosexuals. The case of Bowers v Hardwick opens the door for further discrimination; indeed, this has already been documented in AIDS and the Law (6). Suffice it to say the Supreme Court decision adds legal respectability to the prevalent discrimination against this minority.

It is against this cultural background that we want to discuss three cases of lying or deceiving in HIVinfected persons. Each of these cases presents situations in which the patient deceives or lies to his doctor and/or wants the doctor to deceive or lie to a third party on his behalf. Are such deceptions or lies expressions of compassion? Are they in the patient's best interest? Do they compromise a doctor's integrity?

\section{Case One}

$\mathrm{JM}$, a 32-year-old bisexual man, was diagnosed as having AIDS after he developed Pneumocystis carinii pneumonia. His wife was aware of, and accepting of, his bisexuality. He told his parents of the diagnosis, but said that he had acquired the infection from a tattoo. $\mathrm{He}$ asked his doctor to corroborate his statement, should his doctor ever speak to his parents.

There are several ethical conflicts in this case that are important to identify: these conflicts involve medical confidentiality, autonomy of both patient and doctor, and the manner in which deception intersects with confidentiality and autonomy.

Medical confidentiality is an important feature of the doctor-patient relationship. In general terms, medical confidentiality is non-disclosure of information given to the doctor by the patient that the patient does not wish to be disclosed to third parties without his consent or permission. Why did JM disclose to his doctor that he was bisexual? There were two chief reasons. Firstly, he wanted to provide information about the mode of transmission of HIV infection; he perceived the information as contextually involved with the diagnosis of AIDS. JM believes this is information the doctor ought to know.

Secondly, the familial context: JM's wife knows he is bisexual and on the balance of probabilities she will have a major role in helping him cope with a chronic and fatal disease. In addition he may have transmitted HIV infection to her.

The doctor, in respecting the confidential information disclosed to her/him enhances the patient's autonomy, or self-determination. But the limitations of respect for confidentiality are apparent in a hospital context. The patient's secrets cannot be contained in a one-to-one relationship between revealer and listener. Others who have access to JM's chart in the course of discharging their responsibilities will potentially discover the secrets disclosed in the original patient-doctor consultation.

The presumption needs to be made that all professionals who have access to the chart are aware not only that they are reading the minutiae of a disease, but a transcript of the life of another person, including her/ his secrets, which are inseparably a part of a lived life. Respect for medical confidentiality can rightly be expected by the patient from each professional who has access to it. JM has expressed trust in his primary doctor in sharing or disclosing information that is confidential; the responsible doctor will discuss with JM why this confidential information must be charted and ergo the limitations of medical confidentiality; his secrets will be shared with other health-care providers. But the doctor will also reassure him that the 
confidential information in the chart will remain confidential; the delivery of confidential, quality health-care is the achievement of team-work.

$\mathrm{JM}$ informed his parents of the diagnosis, but said he had acquired the infection from a tattoo. He is aware that the doctor might meet his parents and asks the doctor to lie to them about how he acquired AIDS. If he had said: 'Should you ever meet my parents I don't want you to tell them I am bisexual' he would be requesting legitimate protection of the information he disclosed during the original consultation. His request would be protected by patient-doctor confidentiality (compare by contrast the case discussed at beginning of this paper); but to ask his doctor to lie on his behalf has nothing to do with medical confidentiality. JM perceives the deception as an expression of compassion towards him; what he fails to do is show respect towards the doctor as an autonomous agent. To treat another as an autonomous agent is to concretise the philosophical doctrine of respect for persons; in this case the doctor has shown respect for the patient qua person but the patient is reluctant to accord the same respect to the doctor qua person. The conflict here is between truthfulness/truth-telling which has a central role in the doctor's value-system and conduct, and deception or lying which has a significant role in the patient's value-system.

In medical ethics literature the emphasis is invariably on the patient's autonomy; the autonomy of the doctor is either ignored or rendered innocuous. In fact, in a clinical context there are two autonomous agents - the patient and the doctor.

In the case of JM the doctor refused to assent to his request to lie to his parents for the following reasons: a) truthfulness/truth-telling is a central value in her/his value-system and the value-system forms a fundamental part of her/his way of life; b) the quality of the patient-doctor relationship would be unnecessarily burdened and impaired by deception; c) the crucial elements in health care of trust and confidence would be seriously undermined if not destroyed; d) if the deception were discovered the doctor would be considered to have added credence to the lie, but at the cost of her/his professional integrity; e) if the patient influences the doctor to deceive once, may he not be inclined to do so again? Gradually, what began as a professional relationship between two parties could develop into a confusing network of deceptions in which neither party could believe the words of the other. In this context the patient's fears, anxieties and sufferings would be increased as each withdrew into his own private world inhabited by shadows without substance and truthfulness or truth-telling would be irremediably lost. Deceiving can hardly be construed as the expression of compassion, let alone as being in the patient's best interests.

In case one we discussed, among other things, the problems resulting from a person in authority giving misleading or false information. This point can be illustrated in another case.

\section{Case Two}

ST was a priest who was hospitalised on several occasions because of complications of AIDS. He had received no blood transfusions, had not used IV drugs, and denied any sexual activity. He suggested that he had acquired HIV infection by an unknown route while travelling in South America. He had been diagnosed with a parasitic gastrointestinal infection after his trip, and felt he might have acquired HIV infection at the same time. Because of his particular vocation, he was regarded by his family and many caregivers as an innocent victim. Indeed, this was so deeply believed by health-care providers that they became fearful that unknown modes of transmission might put them at risk during work. The patient's mother accused the doctor of incorrectly diagnosing AIDS, on the premise that her son could not possibly be HIVinfected.

In this case the initial deception by the patient created an environment of fear, suspicion and anger among many of those who sought to help him: the health-care providers. If the patient's doctor had agreed to participate in the deception, or alternatively remained silent about it, her/his professional integrity would have been diminished as would self-respect, the two are fundamentally connected. Further, the efficacy of the health-care providers would have diminished also. In perpetuating the patient's lying (or maintaining silence about it) an atmosphere breeding ignorance, suspicion, anxiety and anger would have been established as a result or consequence of the lack of mutual trust between the patient and the doctor. The element of trust is basic to the relationship between the doctor and the patient, trust between two autonomous persons, but ST did not trust his doctor enough to speak truthfully to her/him.

In this case four different yet connected relationships can be identified, each with its own perspective:

a) The patient-doctor relationship. It is taken for granted that we know the modes of transmission of HIV infection and ergo ST's claim that he contracted it 'by an unknown route while travelling in South America' is false. Also, ST knows his statement is false, he uses it to mislead the doctor; its purpose is to deceive. Yet, there may be another dimension to ST's deception or lying, namely to remain in control of the situation by the kind of information given to the doctor - 'the unknown route' which may also be intended to protect the doctor from any worry she/he might have about a priest having AIDS.

Unlike JM above, ST is a public figure, he is the spiritual leader of a religious community, he is also committed to a vow of chastity as a basic feature of his way of life. The office ST holds defines the kinds of relationships he may have with others. If he actualises our ordinary needs for human and sexual intimacy he does so at the risk of public exposure and possible loss of office, not to mention the possibility of self-loathing. 
It is improbable that ST would share or express, let alone discuss, with his doctor, his need for human intimacy to be actualised in sexual expression. He might trust his innermost secrets with a colleague who lives in another parish; but to share them with a doctor in a hospital would be out of the question.

Or would it? Could ST's awareness of his own dying and impending death break down old habits of thought, and in so doing allow him to accept himself as the person he is, including his need for human intimacy and the expression of the need through sexual relations with another?

In the end ST chose his perception of his own best interests. He chose to stay in control of the situation through lying and deception protected by the authority of his office and expected to be perceived by others as an 'innocent victim' of HIV infection. After all, 'Is it likely a priest would lie or deceive others?' ST believes to state the question is to answer it. In making this choice he rejected the opportunity to become authentic to himself and open to others, in particular, the doctor, health-care providers and his mother.

One of the important differences between the case of $\mathrm{JM}$ and ST is that JM asks the doctor to deceive on his behalf, ST directly deceives the doctor himself. Truthtelling and trust in his relationship with his doctor and health-care providers is not perceived by ST to be in his best interest: the stakes are too high, the risks outweigh the benefits from his point of view. Truth-telling - in the context - does not play a central role in ST's valuesystem: whether he considered the possible or actual consequences of his deception is unknown.

b) the doctor-patient relationship. The doctor believes that mutual trust and truthfulness are basic elements in a clinical context and is sensitive to the corresponding need for respecting confidences revealed to her/him in a medical context. Deception creates suspicion, fear and anxiety; the antidotes to deception are the principles of veracity and trust. ST may well agree with the doctor on this point - but in this context only at a theoretical level - the stigma attached to him as well as the social and professional consequences of these two principles prevent him from embracing them in his relations with his doctor and others. Both ST and the doctor would (probably) agree that each person is unique and worthy of respect and that respect for another's autonomy is a (one might say, the) fundamental way of sharing or expressing individual respect for other persons. (Autonomy has, of course, its limits; Bentham's rule of thumb is pertinent here: Roe's autonomy stops when his umbrella touches Doe's nose.)

The doctor is sensitive, caring and ethical: she/he is a responsible doctor who seeks the enhancement of ST's autonomy through shared decision-making in the management of his illness. Mutual trust and truthfulness maximise communication and benefits and such a relationship engenders openness between persons by allowing each to enter into the other's world. In this, and other ways, we make acknowledgement of our own humanity and the humanity of the other: our common human affinities.

Though ST chose the way of deception and in so doing was unable to realise the open relationship available to him by his doctor, the responsible, caring and ethical doctor would not abandon him. She/he is able to see the patient's vulnerability beyond the deception and while responding to this fragile aspect of his being she/he would not perpetuate the deception he had created.

Would straightforward or abrupt confrontation be appropriate in this case? We submit it would not: confrontation would on the balance of probabilities estrange the patient from the doctor and increase his suffering. He could perceive it as spitefulness or 'getting at him'. It would also close the door on the possibility that he might sometime in the course of his hospitalisation speak to the doctor truthfully about how he acquired the infection and with his consent the doctor could then speak openly to the health-care providers and his mother, thus dispelling the fears, suspicions, anxieties and anger his deception had caused among them. It would also be of cathartic value to the patient. This exchange, did not however, occur. But to say it did not occur is not to say it could not have occurred. In avoiding confrontation with ST the doctor provided a context in which the patient mighb have spoken to her/him truthfully.

The two remaining features to be discussed in thio case are c) the relationship between the health-care providers and the doctor, and d) the relationship between ST's mother and the doctor. Here we shall be brief. In c) the doctor should arrange to have a conference involving all of the health-care providers who participate in the care of ST and should emphasise the modes of transmission of HIV infection: discussion of fears, suspicions, anxieties and anger should be openly and freely expressed. In this way, the involved parties should be allowed of their own volition to arrive at the obvious conclusion, namely ST's lying/ deception. Discussion about why he thought or felt he had to deceive could facilitate mutual understanding of $\mathrm{ST}$ as a person.

d) The relationship between the patient's mother and the doctor. The patient's mother has accused the doctor of incorrectly diagnosing her son; he could not possibly be HIV-infected. The premise implies that ST's mother knows the modes of transmission and excludes her son from each one of these modes. The responsibility of the ethical and caring doctor will be to suggest to the patient's mother that she should discuss her concerns with her son, and with his permission or consent, obtain a second opinion. The doctor's suggestion of obtaining a second opinion has two benefits; one actual, the other potential. It would confirm her/his diagnosis, thereby helping ST's mother to understand her son's medical condition as it really is, thereby correcting her mistaken belief about it. And secondly, confirmation of ST's medical condition could potentially change the quality of the 
relationship, not for the worse but for the better. She might, in this way, come to see her son more fully as a person than she had before, and in so doing, recognise his ordinary needs for human intimacy and sexual expression. The sexual aspect of his being which is a part of his personal identity would be known to her. In this atmosphere ST's perceived need for deception could slip away. Instead of deception mutual trust and unconditional love might be evoked. Whether this happened in this case is unknown. The third case provides a parallel example.

\section{Case Three}

GL, a 42-year-old school principal, moved across the country to live with his parents in a small midwestern town shortly after being diagnosed with AIDS. He made elaborate preparations for his death and funeral. $\mathrm{He}$ indicated that he was in pain and that he could not function at home, and that his elderly parents could no longer bear the burden of caring for him.

Upon admission, his case was treated routinely. $\mathrm{He}$ refused certain comfort measures, stating, 'I've come to the hospital to die' but requested increased doses of intravenous morphine for pain control. The nurses found his attitude alarming, in view of the fact that he was eating well, his pain was easily controlled, and he was observed to move about his room with little difficulty. He continued to enjoy interacting with hospital staff and his parents, as long as he was in control of the interaction. His presence led them to question the motive for hospitalisation and led to suspicion among the hospital staff that the doctor was assisting the patient in suicide. It became clear that his care could easily have been managed at home or in another facility but the patient refused to consider any alternative to hospitalisation. After several care conferences he acknowledged that his condition was not imminently terminal, and he reluctantly accepted transfer to a nearby residential hotel.

Before moving to the midwest GL had lived with his wife and two children in a large city. He told his colleagues that he had leukaemia and that he was going to his parent's home to die since he wished to allow his wife and children to continue their lives without being a burden to them. He sought on-going medical treatment at a large hospital located some distance from his parents' home, so that he could keep his diagnosis secret from other relatives in the area. GL told his doctor that the highest priority in his case was continued confidentiality. He denied sexual activity outside his marriage and there was no history of intravenous drug use. During discussions of potential modes of transmission of infection, he became vague and evasive, avoiding the topic as if it were distasteful to him. His gallbladder had been removed several years before, and he indicated that he might have received a transfusion during this procedure; however, medical records did not substantiate his view.

The patient's concern with confidentiality increased as his illness progressed. Indeed, that his name be linked in any way to AIDS was almost unmentionable, except in circumstances of confidentiality. He refused home care, because this would involve revealing his condition to visiting nurses, who might violate his wishes for total confidentiality. Above all, he feared dying within the county where his parents lived, lest his death-certificate be examined by a curious relative. In the course of discussions about pain control, concerns about assisted-suicide were voiced by both the patient and his mother. The patient's concern focused on the invalidation of his life-insurance policy in the case of suicide; his mother was apprehensive because suicide was incompatible with her religious beliefs.

GL's initial lying to his doctor about the mode of transmission made a relationship based on truthfulness and trust impossible. And during his hospitalisation it led into a complex web of further deceptions. The doctor's concern for the patient's confidentiality was used by GL in a series of manipulative manoeuvres in which the doctor's integrity was called into question by other health-care providers. The discrepancy between the patient's stated condition and the observations of health-care personnel led to questions about motives. One of the central issues in the first case conference focused on the question: 'Did the doctor enter into an agreement with GL about assisting suicide?' In addition, his obsession with confidentiality led eventually to increasing doubt about the veracity of hisce account of how he became infected with HIV. Some time before the last case conference, held this time in GL's room, it was clear to the health-care providers that he was not using the resources of the hospital anymore than he was in need of them. What was being done for the patient in hospital could be done equally well in another facility. Reluctantly, GL agreed and he was discharged to a nearby hotel.

Two weeks after discharge GL made an outpatient appointment with his doctor. In the course of the consultation his doctor quietly asked him how he had become HIV-infected. 'With another man,' he replied. 'I feel so guilty about having AIDS,' he continued, adding, 'I failed myself in not living up to the conventional expectations others have of me, and that I seek to project.' The atmosphere in the room seemed different now, less like a cave inhabited by shadows. More like seeing each other in sunlight, in the real world for the first time. Each of the participants - the patient, his mother, the doctor and the ethicist became more relaxed with each other. The obstacle of deception was at last overcome.

We should ask at this point: 'What do each of the above cases have in common?' and, 'Can the source(s) of the respective deceptions be identified?' It is submitted that the societal attitudes towards male homosexual acts were internalised by the men described in these cases. Thus, a dichotomy was created between the private life and the public image. Fear of condemnation by the doctor or others restricted communication towards the goal of the 
maintenance of the patient's health, their mutual concern. The lack of trust which inhibits truth-telling results in mutual and progressive isolation which impedes the provision of optimal care.

Scott Dunbar PhD and Susan Rehm MD are, respectively, Fellow in Bioethics and Consultant Physician in the Department of Infectious Disease at the Cleveland Clinic Foundation, Cleveland, Ohio, USA.

\section{References}

(1) Dunbar S. An obstructed death and medical ethics. Fournal of medical ethics 1990; 16: 83-87.

(2) Bowers v Hardwick, 106 SCt 2841 (1986).

(3) See reference (2) at 2844.

(4) See reference (2) at 2847.

(5) See reference (2) at 2853.

(6) Senak M S. In: Dalton H L et al, eds. AIDS and the law: a guide for the public. Yale AIDS Law Project, Yale University Press, 1987.

\section{News and Notes}

\section{Call for abstracts}

The VIIth conference of the European Society for Philosophy of Medicine and Health Care will take place in Oslo, Norway, August 19-22,1993. The theme of the conference will be: economics, technology and health care. 'Technology' should be understood in a wide sense to include all medical interventions, say the organisers, who are interested in philosophical aspects of technology assessment and ethical issues in questions of resource allocation in medicine.

They are particularly interested in papers which offer a philosophical analysis of the process by which expensive new interventions, sometimes of doubtful benefit, are introduced into medical practice. Presentations which explore the impact of new interventions for developing countries, such as HIV vaccines, will also be considered. The organisers will, however, in addition consider abstracts on any other topic within the philosophy of medicine and medical ethics for presentations at the conference.

Anyone wishing to present a paper at the conference should submit an abstract of no more than 500 words before February 1, 1993, to: Secretariat ESPMH, Department of Ethics, Philosophy and History of Medicine, Catholic University of Nijmegen, PO Box 9101, 6500 HB Nijmegen, the Netherlands. Fax: 3180540254.

Registration: Anyone wishing to attend the conference should fill in a registration form which is available from the Centre for Medical Ethics in Oslo. Two full days of programme (August 20-21) are planned, with arrival on August 19 and departure on August 22. All inquiries about organisational matters of the conference should be addressed to: Centre for Medical Ethics, University of Oslo, Gaustadalleen 21, N-0371 Oslo, Norway. 